\title{
Biopolítica, necropolítica y pandemia. Notas sobre el neoliberalismo y la desigualdad social en Chile
}

\author{
Biopolitics, necropolitics and pandemic. \\ Notes about neoliberalism and social inequality in Chile \\ Juan Pablo Silva-Escobar \\ Centro de Investigación en Artes y Humanidades (CIAH)- \\ Facultad de Artes Universidad Mayor-Chile. \\ juan.silvae@umayor.cl
}

\section{Resumen}

El objetivo de este trabajo es reflexionar sobre algunos de los aspectos sociopolíticos y culturales que han ocurrido en Chile a raíz de la pandemia del Covid-19. Para ello se ha estructurado el texto en tres secciones. En la primera se abordan los conceptos de biopolítica (Foucault) y necropolítica (Mbembe), con los cuales se analiza el modo en que el gobierno de Piñera ha privilegiado la economía como política de la vida (biopolítica), gestionando quienes pueden vivir y a quienes dejar morir (necropolítica), y ha instalado el discurso de la política como guerra en el contexto de un estado de excepción como paradigma de gobierno (Agamben). La segunda sección examina tres ejemplos que permiten elaborar una crítica a los procesos de despolitización, desconexión y banalización del gobierno ante la crisis sanitaria. Finalmente, se lleva a cabo una reflexión sobre las ollas comunes como práctica cultural que contribuye en la repolitización de los barrios.

Palabras clave: Despolitización; repolitización; gastropolítica, movimientos sociales.

\begin{abstract}
The objective of this work is to reflect on some of the sociopolitical and cultural aspects of what has happened in Chile in the wake of the Covid-19 pandemic. To this end, the text has been structured into three sections. The first addresses the concepts of biopolitics (Foucault) and necropolitics (Mbembe), which analyze how Piñera's government has privileged the economy as a policy of life (biopolitics), managing those who can live and those who let die (necropolitics), and has installed the discourse of politic as war in the context of a state of emergency as a paradigm of government (Agamben). The second section examines three examples that allow to develop a critique of the government's processes of depoliticization, disconnection and trivialization of the health crisis. Finally, a reflection is carried out on the "Ollas comunes" as a cultural practice that contributes to the re-politization of the neighborhoods.
\end{abstract}

Keywords: Depoliticization; repoliticization; gastropolitics; social movements. 


\section{Introducción}

La covid no cayó del cielo, no salió de una sopa de murciélago en un rincón de Wuhan, forma parte de un sistema. No en el sentido new age, como una venganza espiritual de la naturaleza contra el capitalismo. La covides materialismo puro, un proceso vacío de significado, algo que simplemente ocurre, pero por supuesto que lo hace en unas condiciones económicas determinadas.

\section{Slavoj Žižek}

Según Alain Badiou, la complejidad de una pandemia se debe a que ésta "siempre es un punto de articulación entre determinaciones naturales y determinaciones sociales" (2020: 71). Ese proceso, pone en tensión no solo coyunturas de orden biológico, sino también pone a prueba la capacidad que tienen los Estados para resolver las emergencias sociales que vienen aparejadas a estas situaciones límites. Uno de los aspectos sociopolíticos que se evidencian producto de la crisis sanitaria, es la incapacidad que ha exhibido el gobierno chileno para hacerse cargo y dar respuestas a las problemáticas socioeconómicas que están afectando a gran parte de la población, especialmente la más vulnerable. Esta incapacidad puede atribuirse a que la modernización neoliberal no ha sido más que un maquillaje, una cosmética que ha traspasado muchas de las responsabilidades sociales al mundo privado. De modo que el neoliberalismo no es una forma de gobernar sino una forma de gobierno que establece "relaciones estrictamente mercantiles en la sociedad" (Foucault, 2016: 155); de ahí que "la vitalpolitik, la política de la vida (...) de la que Rüstow hablaba (...), es la de construir una trama social en las que las unidades básicas tengan precisamente la forma de la empresa" (Foucault, 2016: 186). Así, a la hora de implementar políticas públicas de contención de la pandemia, éstas están supeditadas a criterios económicos, cálculos de utilidad de costo y beneficio, que tienen por finalidad ser aplicados en ámbitos no económicos, que hace del ciudadano ya no un sujeto de derechos sino de emprendimientos, de competencias, de capital humano, de autogestión, empresarización, y que tiene por horizonte político colonizar todos los ámbitos de la sociedad, de la vida y de la muerte $\mathrm{y}$, por consiguiente, hacer del mercado "el poder informante de la sociedad" (Foucault, 2016: 186). Si la mercantilización neoliberal ha sido eficiente a la hora de colonizar todos los ámbitos de la vida social-familia, educación, salud, trabajo, etc.-se debe a que la política muta hacia una burocracia administrativa, que gestiona pero no transforma.

La condición neoliberal ha sido eficaz a la hora de establecer un proceso de despolitización de la sociedad chilena, proceso que ha contribuido a instaurar una democracia liminal, de baja intensidad política, y sumida en una crisis de legitimidad (Mayol, 2014). La deslegitimación de la política y la despolitización de la sociedad se establecen como condición de posibilidad para consolidar la hegemonía neoliberal como un 
poder sobre la vida que busca establecer orden en un contexto de contingencia (Mouffe, 2011). Si el poder político no responde a las demandas de la sociedad, si es incapaz de ser un contrapeso del poder económico, y si los ciudadanos ven al poder político como un instrumento al servicio de intereses económicos, el resultado es una crisis de legitimidad de la institucionalidad política que se traduce en indignación y malestar social frente al abuso del poder económico y frente a la inoperancia de la política institucional (Atria, et. al., 2014). Por lo tanto, la deslegitimación de la política y la despolitización de la sociedad no son políticamente neutrales, por el contrario, es la respuesta esperada a los cuarenta años del dominio neoliberal como racionalidad. Ante esta hegemonía, y a partir del estallido social del 18 de octubre de 2019, los movimientos sociales y ciudadanos han llevado adelante un proceso de repolitización e impugnación del neoliberalismo que ha sido particularmente oportuno durante la pandemia, porque permitió recuperar los espacios sociales, las prácticas culturales y hacer de lo público y lo comunitario un espacio de deliberación política y solidaridad social.

Sostengo que el neoliberalismo requiere para su funcionamiento ejercer un control sobre la población como masa cuantificable y, al mismo tiempo, necesita ir profundizando en los procesos de despolitización y desigualdad social. En tal sentido, se advierte que la despolitización y la desigualdad social se han intensificado en el segundo gobierno de Sebastián Piñera (2018-2022). A partir del estallido social del 18 octubre 2019 y con la actual crisis sanitaria del coronavirus, se evidencia que la despolitización no solo opera como un dispositivo que persigue neutralizar y deslegitimar a los movimientos sociales; sino también actúa hacia el interior del gobierno y se traduce no solo en una desconexión radical entre la clase gobernante y la ciudadanía, lo cual tiene como una de sus consecuencias el incremento de la desigualdad social. En respuesta a esta desconexión, banalización y despolitización de la sociedad, los movimientos sociales y ciudadanos han llevado adelante un proceso de organización comunitaria y de repolitización, que se traduce en la recuperación de espacios sociales y prácticas culturales que vienen a evidenciar que lo público y lo comunitario son el fundamento de lo político.

El texto está estructurado en tres apartados más una conclusión. En el primero se abordan los conceptos de biopolítica y necropolítica, con los cuales se buscó establecer no solo cómo el gobierno de Piñera ha privilegiado la economía como política de la vida (biopolítica), gestionando quienes pueden vivir y quienes deben morir (necropolítica), sino también ambos conceptos me permitieron analizar el discurso sobre la política como guerra, que insistentemente ha instalado el gobierno de Piñera. En la segunda sección analizo tres ejemplos que me permitieron elaborar una crítica a los procesos de despolitización, desconexión y banalización de la política en la actual crisis sanitaria. En la tercera sección llevo a cabo una reflexión sobre las ollas comunes como práctica cultural que ha resurgido a raíz de la dramática crisis socio-sanitaria, y que vienen a repolitizar lo comunitario, a partir de la problemática del hambre e instalar lo que Arjun Appadurai (1981) y Sonia Moncetino y Rolf Foerster (2012) llaman gastropolítica. Finalmente, en las conclusiones 
se lleva a cabo una síntesis de las principales reflexiones en torno a la pandemia, la desigualdad social, el neoliberalismo y el estado de excepción y técnica de gobierno.

\section{Biopolítica, necropolítica y gubernamentalidad neoliberal}

En la última clase del curso Defender la sociedad del día 17 de marzo de 1976, Michel Foucault (2000) realizó una distinción clave respecto de los mecanismos disciplinarios y los dispositivos de seguridad. Señala que los dispositivos disciplinarios se configuran como un poder centrado en controlar al individuo a través de un conjunto de técnicas que persiguen intervenir, conducir y manipular al individuo, para ello, se conforma todo un entramado institucional que "trata de regir [sobre] la multiplicidad de los hombres [y de las mujeres] en la medida en que esa multiplicidad puede y debe resolverse en cuerpos individuales que hay que vigilar, adiestrar, utilizar y, eventualmente, castigar" (Foucault, 2000, p. 220). De este modo, las técnicas disciplinarias buscan gobernar la singularidad de los sujetos y, con ello, se origina un conjunto de "efectos individualizadores, [que] manipula el cuerpo como foco de fuerzas que hay que hacer útiles y dóciles a la vez" (Foucault, 2000, p. 225). En cambio, los dispositivos de seguridad no están centrados en la individualización, sino que tratan una problemática mayor, donde la categoría de individuo pasa a un segundo plano e irrumpe un nuevo dominio llamado población. Esta nueva técnica de poder no excluye las técnicas disciplinarias, sino más bien las envuelve, las reutiliza, las transforma parcialmente y las lleva al nivel de la biopolítica.
De acuerdo con Foucault (2006; 2016), la biopolítica es una técnica de poder y de control que eclosiona con el liberalismo del siglo XVIIII, y tiene por objeto gestionar y normalizar la vida social de las poblaciones, a través de una serie de procedimientos destinados a fiscalizar, vigilar, encauzar e intervenir en aquellos aspectos como el matrimonio, las enfermedades, la sexualidad, el crimen, etc. Una de sus características es ligar la biología con la economía al punto de hacerlas inseparables. La biopolítica en cuanto dispositivo de control de la economía política se encuentra anudado a una problemática mayor, que dice relación con la emergencia de aquello que se ha llamado "gestión de gobierno"; ello comprende una nueva racionalidad gubernamental que se ejerce sobre el conjunto de la población, y tiene por finalidad cuantificar, maximizar y moldear a los grupos sociales. La biopolítica en tanto gobierno de la vida de las poblaciones se encuentra directamente relacionada con la noción de gubernamentalidad, concepto que le permite a Foucault (2006) introducir las relaciones de poder en términos de una microfísica del poder, por una parte; y por la otra, analizar la forma en que los individuos son dirigidos y se conducen a sí mismos.

La noción de gubernamentalidad implica, entonces, por una parte, entenderla como una gubernamentalidad política, que tiene directa relación con "el análisis de formas de racionalidad, de procedimientos técnicos, de formas de instrumentalización" (Castro, 2018: 192). Por otra parte, la gubernamentalidad se encuentra relacionada con aquellas técnicas de dominación ejercidas sobre los individuos en tanto pertenecientes a 
un grupo poblacional. De modo que tiene que ver tanto con la manera en que los sujetos son dirigidos y con la manera en que se conducen a sí mismos (Foucault, 2006, 2013, Castro, 2018). Por otro lado, me perece necesario recalcar que el concepto de gubernamentalidad, en ningún caso implica una sucesión o una sustitución secuencial de una sociedad de soberanía por una sociedad disciplinaria y de ésta hacia una sociedad de gobierno o poblacional, sino más bien se trata de "un triángulo: soberanía, disciplina y gestión gubernamental, una gestión cuyo blanco principal es la población y cuyos mecanismos esenciales son los dispositivos de seguridad" (Foucault, 2006, p. 135). De ahí que la noción de gubernamentalidad nos introduce en un domino más amplio de análisis, que nos puede ser útil para entender el modo en que la actual crisis sanitaria del coronavirus ha sido abordada como un poder sobre la vida (y de la muerte), evidenciando la necesidad de controlar, manipular y clasificar la experiencia pandémica, a través de los dispositivos de seguridad, los mecanismos disciplinarios y por la intervención biopolítica.

Ahora bien, si la consolidación del neoliberalismo redujo el poder político a una burocracia administrativa que hace de éste un poder carente de poder, la biopolítica, en tanto dispositivo de control que interviene sobre la vida de la población como masa susceptible de ser cuantificada, se establece como "un elemento indispensable en el desarrollo del capitalismo; éste no pudo afirmarse sino al precio de la inserción controlada de los cuerpos en el aparato de producción y mediante un ajuste de los fenómenos de población a los procesos económicos" (Foucault, 2013:
133). La biopolítica exhibe, entonces, el modo en que el "umbral de la modernidad biológica" (Foucault, 2013: 135), introdujo un conjunto de operaciones de poder que permitieron establecer la primacía económica como un poder sobre la vida, que hace de las poblaciones, una variable específica de intervención gubernamental. De ahí que "la población es un conjunto de procesos (no de personas), y el 'arte de gobernar' debe conocer estos procesos a fondo con el fin de generar técnicas específicas que permitan gobernarlos" (Castro-Gómez, 2015: 63). De esta manera, el neoliberalismo instituye un conjunto de técnicas de gobierno, como por ejemplo, el uso subjetivo del miedo como dispositivo de control, [1] el consumo como mecanismo de distinción social, y como se ha revelado dramáticamente recientemente, e, la gestión de la pandemia a partir de criterios de costo-beneficio.

Si la gubernamentalidad neoliberal está impregnada de presunciones biopolíticas que se materializan como técnicas de gobierno, es porque ellas apuntan a establecer el dominio económico como un poder sobre la vida que conlleva, al mismo tiempo, un poder sobre la muerte, puesto que "hacer vivir entraña decisiones implícitas y a veces explícitas para determinar quién vivirá qué tipo de vida y durante cuánto tiempo" (Fassin, 2018: 38). De ahí, que me parezca pertinente, recurrir al concepto de necropolítica desarrollado por Achille Mbembe (2011), pues éste abre la posibilidad de incorporar a la gestión de la vida la variable de la regulación de la muerte.

La necropolítica permite comprender el modo en que el gobierno de Sebastián Piñera ha gestionado 
la crisis del Covid-19 a partir del esquema "dejar morir, hacer vivir"; y con ello, se apunta a la hipótesis de que "la soberanía reside ampliamente en el poder y la capacidad de decidir quién puede vivir y quien debe morir" (Mbembe, 2011: 19). Esta soberanía se constituye como uno de los cimientos ideológicos del neoliberalismo en el tercer mundo, puesto que permite legitimar y naturalizar la cosificación de los seres humanos como cuerpos desprendidos de cualquier subjetividad, convirtiéndolos en mercancía susceptible de ser desechada. Una de las formas en las que operaría esta necropolítica, sería la segmentación y categorización de la población de acuerdo a escalas de valores que cuantifican y clasifican la vida humana según las diversas posiciones que ocupan según su clase, etnia, género, etc., y se constituyen en índices que definen a quiénes hacer vivir y a quienes dejar morir (Mbembe, 2011).

Por otro lado, los conceptos de bio/necropolítica abren la posibilidad de analizar el discurso de la política como una forma de guerra. Esta discursividad instala al enemigo -externo o interno- para instaurar una soberanía sustentada en la reducción de esta amenaza, y promueve los mecanismos defensivos de la comunidad frente al enemigo (Moraña, 2014). Foucault define "la política como la continuación de la guerra por otros medios" (2000: 53); mientras que Mbembe plantea que "la guerra también es un medio de establecer la soberanía, tanto como un modo de ejercer el derecho a dar la muerte" (2011: 20). En distintos momentos históricos la política chilena se ha articulado, al menos parcialmente, sobre la base de combatir a un enemigo interno: los mapuches durante "la pacificación" de la Araucanía, los marxistas durante la dictadura de Pinochet, la delincuencia durante la transición a la democracia. Hoy en día, la política como guerra es un discurso al cual se recurre indistintamente para deslegitimar al adversario político (los movimientos sociales), para nombrar un problema de orden social (la delincuencia), o para designar una crisis sanitaria. Por ejemplo, el 7 de abril del 2018, en una ceremonia con Carabineros, el presidente Piñera señaló, refiriéndose a la delincuencia, que "todos los chilenos tenemos que unirnos frente a un enemigo poderoso e implacable, que no respeta a nada ni a nadie". El 20 de octubre, en pleno estallido social, el presidente repitió que "estamos en guerra contra un enemigo poderoso, implacable y que no respeta a nada ni a nadie". Finalmente, en medio de crisis sanitaria del Covid-19, el mandatario volvió a señalar, el 12 de abril de 2020, que "sabemos que el coronavirus es un enemigo poderoso, cruel, implacable y que no respeta a nadie".[2]

Este discurso reiterativo del presidente, que lleva el aforismo Clausewitz -"la guerra es la continuación de la política por otros medios" (2005: 31)- a su límite extremo, hace de la política un imposible en tanto presenta una problemática que ya no puede ser abordada desde la política deliberativa y, por ende, lleva a la política a un desborde de violencia (Avelar, 2016). Este tipo de discursividad permite al gobierno de Piñera justificar "los procedimientos biopolíticos [y necropolíticos] (...) al punto extremo de su poder coercitivo, imprimiéndoles un vuelco tanatológico" (Esposito, 2011: 176). En tal sentido, permite llevar adelante una administración sobre la vida (biopolítica), justificar una política del dejar morir 
(necropolítica), y abre el camino para el establecimiento del estado de excepción que naturaliza y legitima lo que es "una medida provisional y excepcional en técnica de gobierno, (...) [que] se presenta (...) como un umbral de indeterminación entre democracia y absolutismo" (Agamben, 2010: 11). Esto se ha traducido en una serie de políticas públicas, tales como: la facilitación de los despidos, endeudamiento de las familias, cuarentenas parciales que obligan a salir a trabajar, negación de ayudas económicas a las familias más vulnerables, entre otros.

En suma, la bio/necropolítica se establecen como fundamento y base normativa para una gubernamentalidad neoliberal del hacer vivir y el dejar morir, que para el caso chileno ha venido mostrando de manera sistemática, un vínculo muy estrecho con la condición de clase. Con la crisis socio-sanitaria se ha hecho aún más evidente que hay una relación directa entre clase privilegiada y probabilidad de sobrevivir, mientras que a menor posición social mayor será la probabilidad morir; volviendo a inscribir, como ha observado Judith Buttler (2020: 62), "la distinción espuria entre vidas dolorosas e ingratas, es decir, aquellos quienes a toda costa serán protegidos de la muerte y esas vidas que se considera que no vale la pena que sean protegidas de la enfermedad y la muerte".

\section{Despolitización, desconexión y banalización}

La despolitización que el neoliberalismo promueve y la desconexión con las problemáticas sociales que el gobierno de Piñera muestra de manera sistemática para contener la crisis sanitaria, es sintomática de una manera de concebir el arte de gobernar y contribuyen de manera significativa a profundizar la desigualdad social en Chile. En tal sentido, se advierte que a partir del estallido social de octubre 2019 y con la actual crisis sanitaria, la despolitización no solo opera como un dispositivo que persigue neutralizar y deslegitimar a los movimientos sociales, sino también actúa hacia el interior del gobierno y se traduce como una desconexión radical entre la clase gobernante y la ciudadanía.

Un ejemplo claro de cómo ha operado la despolitización, la desconexión y la banalización de la política en la actual crisis socio-sanitaria, es lo que ocurrió el 18 de mayo de 2020. Ese día, vecinos de la comuna de El Bosque salieron a protestar en pos de conseguir algún tipo ayuda para paliar el hambre; ese mismo día, la presidencia llamó a una licitación con un presupuesto inicial de cien millones de pesos para adquirir "suministros de productos gourmet". La explicación que se ofreció fue que "buscaban abastecer la cocina de La Moneda de productos para eventos de alto nivel". [3] Esta banalidad y superficialidad no es un error de procedimiento o un desliz comunicacional, sino una forma naturalizada de concebir la esfera política de acuerdo a lo que Bourdieu (2019) llama una sociodicea de sus propios privilegios, que les permite justificar su existencia como dominantes, y establecer que sus privilegios como cuestiones que se merecen por derecho propio y que no revisten discusión, porque "el mundo está hecho para ser dominados por ellos” (Bourdieu, 2019: 528).

La banalización, la desconexión y la despolitización también queda en evidencia en las declaraciones de las autoridades de gobierno a los medios de 
comunicación, y que demuestran que el profundo grado de desconocimiento de la precariedad socioeconómica que aqueja a la mayoría de las familias chilenas no es una cuestión puntual sino estructural del gobierno. Un ejemplo de esto son las declaraciones que ofreció en un programa de televisión el entonces ministro de salud, Jaime Mañalich, quien señaló que las diferencias observadas en contagios y efectividad de las cuarentenas en Santiago, se debía a que "hay un nivel de pobreza y hacinamiento, (...) del cual yo no tenía conciencia de la magnitud".[4] Este desconocimiento puede ser leído como una forma de neutralizar la realidad social, es decir, evidencia la capacidad que tiene la institucionalidad política para desconocer, desentenderse e ignorar la realidad socioeconómica como un problema político que requiere atención y solución (Atria, 2013).

Hay un tercer ejemplo que me parece aún más revelador. Se trata del Plan de Apoyo Especial para la Clase Media. Este plan "incluye la postergación de créditos hipotecarios con garantía estatal, préstamos blandos para darles recursos de inmediato, una ampliación del subsidio de arriendo y del crédito a la educación superior". [5] No deja de ser sintomático el hecho de que se proponga como solución a la crisis económica el endeudamiento de los hogares endeudados.[6] Esta política pública se constituye, entonces, como un eufemismo de protección social, que funciona bajo la lógica del hacer ver y el hacer creer que se está entregando un beneficio social, cuando en el fondo se están entregando facilidades para el acceso al crédito. Esto es revelador de cómo las políticas públicas se han institucionalizado como mecanismos destinados a beneficiar a la clase dominante.

Estos ejemplos tienen como trasfondo político lo que Pierre Bourdieu (2019) llama "actitud dóxica”, es decir, el conjunto de creencias, prácticas y discursos que se imponen socialmente de manera prereflexiva, infraincosciente, preexplícita e infraverbal, y que no admiten discusión porque se encuentran totalmente integradas y naturalizadas dentro de un grupo histórico -en este caso la clase dominante representada por el gobierno. Desde esa posición de dominio es imposible que reconozcan que esta actitud dóxica conlleva una forma actualizada de violencia simbólica, permitiendo establecer posiciones de poder y privilegio, distribuir creencias y valores que reclaman no solo el reconocimiento y la legitimidad social para dominar, sino también su obligación de hacerlo.

\section{Ollas Comunes, gastropolítica y repolitización}

La agudización del hambre se ha intensificado de manera dramática a raíz de la pandemia del Covid-19. Si en Chile, antes de la crisis socio-sanitaria, había “600 mil personas con inseguridad alimentaria severa (...), ahora podrían sumarse 400 mil personas, lo que implica que el escenario es de hasta un millón de personas que podrían verse privadas de alimentos nutritivos hasta por varios días".[7] Hambre y pobreza no solo están evidenciando la precariedad social que conlleva el neoliberalismo y la inoperancia política del gobierno para salvaguardar a las clases más desposeídas de la sociedad, sino que vienen cuestionar las estructuras ocultas, subyacentes que organizan la reproducción material y social de la 
sociedad neoliberal. "Si hay hambre y pobreza, la sociedad no parece estar organizada de manera de garantizar la vida de todos, sino en función de criterios y valores de exclusión social" (Gallardo, 1985: 2).

Hambre y pobreza es una constante que atraviesa nuestra historia, sin embargo en las últimas décadas estas problemáticas desaparecieron del discurso público. La calificación de "clase media" de un amplio porcentaje de la población que, en estricto, vive con ingresos cercanos al mínimo pero que a través de créditos ha obtenido bienes de consumo antes inalcanzables y que la tienen profundamente endeudada, ha contribuido a maquillar la realidad social y a hacer de Chile una suerte de "aldea Potemkin".[8] Eso, sumado a la exhibición de cifras macroeconómicas y la complicidad de los medios de comunicación, mantuvo la ilusión de que Chile estaba a un paso del desarrollo. Sin embargo, esta imagen anhelada de ser un país del primer mundo comenzó a tensionarse a partir de una serie de movilizaciones sociales, que finalmente confluyeron en el estallido social del 18 de octubre de 2019, [9] en el que por primera vez se impugnó la totalidad del modelo. La actual crisis socio-sanitaria y del coronavirus no ha hecho más que evidenciar aún más las desigualdades y ha reforzado la necesidad de un nuevo pacto social que transforme al Estado subsidiario en un Estado de derechos.

Ante la desprotección social que el neoliberalismo promueve, antela instauración de la despolitización como racionalidad neoliberal que persigue la desactivación política de la población, ante los diversos procedimientos biopolíticosy necropolíticos que el gobierno ha implementado para la contención de la pandemia, ante la banalización y desconexión como estrategia para la gestión del Estado; frente a toda esta violencia física y simbólica que se ejerce sobre la población -en especial en contra de la población más desposeída-, emergen movimientos sociales y ciudadanos que buscan llevar a cabo un trabajo de repolitización de las comunidades a través de la recuperación de espacios sociales (plazas, calles, barrios) y de prácticas culturales (en el sentido antropológico del término),[10] que vienen a reinstalar la idea de que lo público y lo comunitario son el fundamento de lo político y que "la política ocurre cuando aquellos que "no tienen' el tiempo se toman este tiempo necesario para plantearse como habitantes de un espacio común" (Ranciére, 2011: 34).

Una de las prácticas culturales que ha resurgido como un espacio político de reapropiación de lo comunitario son las ollas comunes que, como observó Clarisa Hardy en un estudio que realizó en dictadura, dan cuenta del modo en que el neoliberalismo "afecta tan severamente a los pobladores que surge, entre otros impactos, el problema de la alimentación. Pero la olla es más que la necesidad de comer, algo distinto a la sola expresión del hambre en los sectores populares" (1986: 22). Me parece necesario señalar que las ollas comunes actuales, producto de las transformaciones sociales, culturales, políticas y tecnológicas de los últimos treinta años y de la situación de pandemia en las que operan, generan nuevas formas de organización social que difieren de los análisis que se hayan hecho durante la dictadura respecto de su funcionamiento.[11] No obstante, ya sea a principios del siglo veinte, en dictadura 
o en pandemia, las ollas comunes, se constituyen como espacios de resistencia que se articulan a partir de procesos colectivos de acción comunitaria, que contribuyen a la recomposición del tejido social porque revierte mediante mecanismos de reciprocidad, aquello que en el imaginario neoliberal es individualización, consumismo y despolitización. Las ollas comunes como espacios de repolitización y reconfiguración de lo comunitario, ponen en marcha acciones (recolectar alimentos, cocinar, distribuir raciones) y sentidos (comunitario, solidario y político) que van más allá de ser un paliativo para el hambre, porque las ollas comunes "entroncan con los diversos tipos de movilizaciones y formas de lucha que han desarrollado los sectores populares frente al problema del hambre" (Gallardo, 1985: 14).[12]

Uno de los aspectos que me parece relevante de las ollas comunes que están funcionando al día de hoy,[13] es que éstas se instituyen como una práctica cultural que hace del barrio un espacio de mediación dialéctica, es decir, vincula el nivel personal (el hogar, la familia, el adentro) con el nivel social (la calle, los vecinos, el afuera). La olla común se articula como acción política constituida sobre la base de una relación comunitaria entre vecinos organizados (Hardy, 1986; Mayol, 2006). Así, en esta relación dialéctica, la olla común se inscribe como una huella indeleble de reapropiación del espacio comunitario, de repolitización de lo social que, a partir del drama de la pobreza extrema y del hambre que ella acarrea, constituye una forma de organización comunitaria "que descansa en la asociación de recursos y trabajo colectivo" (Hardy, 1986: 28). Las ollas comunes son comunidades de cuidado, en las que se entrelaza la vida cotidiana pública con la vida cotidiana privada y, en ese cruce, se fortalece lo comunitario y la acción política en donde todas las vidas importan.

En tal sentido, las ollas comunes que han proliferado producto de la pandemia pueden ser leídas a luz del concepto de gastropolítica. De acuerdo con Arjun Appadurai (1981), los alimentos no son solo nutrientes, proteínas o vitaminas, son también un dispositivo semiótico en el que se inscriben relaciones culturales, sociales y políticas en las que tienen lugar relaciones de producción e intercambio cultural. La comida, al constituirse material y simbólicamente como un sistema de significación, deja entrever las condiciones entre campo y mercado, entre abundancia y escasez, permite conocer las diversas formas, contextos y funciones que cumplen en una determinada sociedad los alimentos, o bien puede indicar rango y rivalidad, solidaridad y comunidad, identidad o exclusión, cercanía o distancia (Appadurai 1981; Geertz, 2003; Montecino, 2021). De ahí que la elaboración de los alimentos se constituye como un hecho social y una manera de representación colectiva imbuida de prácticas culturales que, como Lévi-Strauss (1966) ha sugerido a partir de lo crudo, lo cocido y lo podrido, los alimentos codifican sutiles propuestas cosmológicas. En consecuencia, la gastropolítica puede ser entendida "como un proceso en el cual el alimento es al mismo tiempo el medio y el mensaje de un conflicto" (Montecino y Foerster 2012: 144). De ahí que la gastropolítica se configure como un concepto mediador que salva las distancias entre los recursos culturales y económicos, entre lo femenino y lo masculino, entre lo individual y 
lo colectivo, entre lo privado y lo público. Esto quiere decir que la gastropolítica no es un concepto cerrado, sino por el contrario, se trata de una problemática sujeta a diferentes cambios históricos, deslizamientos, transformaciones socioculturales y políticos en ambas laderas (medio y mensaje) de su función mediadora.

En consecuencia, la proliferación de ollas comunes en el país viene a signar la problemática del hambre como un conflicto social que repercute en distintas direcciones y sentidos; tales como la inseguridad alimentaria, la inoperancia del estado neoliberal, la función política de la comida en un contexto de desigualdad social, el liderazgo y politicidad femenina, entre otras. De este modo, la comida que se elabora en el marco de las ollas comunitarias -la mayoría de ellas sustentadas y lideradas por mujeres que asumen la responsabilidad de nutrir y alimentar a la comunidad empobrecida-, se constituyen no solo como una práctica cultural que cumple la función de satisfacer una necesidad básica, sino también establecen una gastropolítica que transforma la práctica culinaria -por lo general asociada al espacio doméstico y privado-en una práctica que se toma lo público y lo subvierte como una forma de lucha y denuncia, puesto que las ollas comunes (y la comida que allí se prepara) reverberan en la actual crisis socio-sanitaria y política, dejando entrever la fuerza semiótica de los alimentos que, al convertir la comida en un dispositivo político animado por prácticas culturales específicas y movilizado dentro de contextos sociales y políticos particulares, hacen que la comida, en sus diversas expresiones y funciones, sea al mismo tiempo, una necesidad básica (un bien perecedero), y un dispositivo político (un discurso de poder o de contrapoder) (Appadurai, 1981). En suma, la gastropolítica que se inscribe en las ollas comunes, contribuye a significar el mundo y hace de los alimentos un sistema cultural, un sistema de símbolos, categorías y significados que se encuentran en tensión y en relación con la organización social, cultural y política de un contexto histórico particular; pues, como decía aquella pancarta enarbolada en el marco de la revuelta social del 18 de octubre 2019: "la dignidad se cocina a fuego lento".

\section{Conclusiones}

Los procedimientos biopolíticos/necropolíticos, el estado de excepción, los procesos de despolitización y deslegitimación de la política, así como la banalización y desconexión que ha evidenciado el gobierno de Piñera a lo largo de la pandemia, no son solo una cuestión de discursos, dispositivos y estrategias, son también técnicas de gobierno que se materializan y afectan las vidas de las personas y de los grupos sociales de manera concreta; porque la política, en última instancia, como ha observado Didier Fassin (2018), gobierna vidas, se manifiesta en cuerpos, procede de elecciones morales que inciden en el modo en cómo se trata a la población, y establece la forma en que las vidas individuales y grupales son definidas y valoradas socialmente. Desde un tiempo a esta parte, muchos de los dogmas y principios instalados por el neoliberalismo están siendo impugnados desde los movimientos sociales, la academia, las organizaciones de la sociedad civil y los partidos políticos de izquierda. Con la actual crisis sanitaria esas objeciones han tenido mayor notoriedad, 
evidenciando que muchos de los problemas sociales (cesantía, hambruna, precariedad laboral, educativa, sanitaria, etc.), no tienen una respuesta desde la institucionalidad política, porque ésta se encuentra subordinada al poder económico como un poder sobre la vida.

Los más de cuarenta años de estructuración neoliberal han establecido una forma de dominación económica, política, cultural y social, que ha demostrado su inoperancia para enfrentar, por ejemplo, las consecuencias de la pandemia, corroborando que la modernización neoliberal en Chile es la expresión de una falsa modernización (Mayol y Ahumada, 2015). El rediseño que el neoliberalismo hizo de la relación entre Estado y mercado, “impactó en las formas que adquirieron los desafíos estructurales de la vida social, al mismo tiempo que introdujo la imagen de una sociedad perfectamente móvil y competitiva" (Araujo, 2017). Esto redujo el poder del Estado cuya función ha sido la de convertir la vida social en un mercado, contribuyendo a establecer un entramado social que tiende a estructurar la sociedad como una terrible fábrica de riqueza y miseria, que tiene como resultado "la constitución de una sociedad dual, estructurada a dos velocidades y que coagula en un verdadero apartheid social" (Boron, 1999: 97). Así, no es de extrañarnos que a la hora de implementar políticas públicas de contención de la pandemia, éstas estén supeditadas a criterios económicos, cálculos de costo y beneficio, que son aplicados en ámbitos no económicos y que hacen "del mercado, de la competencia, y por consiguiente de la empresa, lo que podríamos llamar el poder informante de la sociedad" (Foucault, 2016: 186).
La lucha contra el neoliberalismo como poder informante de la sociedad chilena, se ha venido dando a través de un paulatino proceso de repolitización iniciado el 2006 con la movilización de los estudiantes secundarios en contra del lucro en la educación; prosiguió con las movilizaciones de los universitarios el 2011 y su demanda de la gratuidad de la educación superior entendiéndola como derecho social; posteriormente, el 2016, emergieron las movilizaciones que demandaban el fin de las AFP, poniendo en tensión el actual sistema de pensiones; continúo el 2017 con el movimiento feminista y su lucha contra del patriarcado y el machismo. Además, en estos últimos quince años hemos visto aparecer una serie de conflictos y movilizaciones -de diverso calibre-medioambientales, regionales, laborales; y finalmente, el 18 de octubre 2019 eclosiona la gran revuelta social, que viene a congregar a una gran masa heterogénea, a una diversidad de demandas que, reunidas bajo la consigna política de “Chile despertó", confluyen en el espacio público para repensar su condición de pueblo -un pueblo engendrado por la racionalidad neoliberal-, que se reconoce en su intento por reconstruir lo comunitario, romper con su dispersión, y constituirse como un nuevo pueblo (Ruiz, 2020). Si bien este nuevo pueblo se instituye como una nueva subjetividad política, ésta irrumpe en la estructura social y política de manera informal, desarticulada, sin liderazgos y con una profunda desconfianza en la política institucional.

No obstante ello, este nuevo pueblo ha conseguido fundar una crítica al neoliberalismo a través de prácticas contrahegemónicas-movilización social, asambleas autoconvocadas, ollas comunes, etc.-, 
que desafían la hegemonía neoliberal, promueven la deliberación pública como un espacio de poder, conflicto y antagonismo (Mouffe, 2011). Por otro lado, a partir del estallido social han resurgido un conjunto de prácticas culturales que buscan romper con el encapsulamiento de la sociedad como cuerpo de individuos desconectados social, cultural y políticamente. Esto último, a mi modo de ver, ha sido fundamental para poder enfrentar la pandemia desde la organización social, puesto que la repolitización de lo comunitario -como lo atestiguan las ollas comunes-, viene a recomponer el barrio como un espacio colectivo, solidario y político, en un momento en el que si individualismo es la norma, hacer comunidad es revolucionario (Solnit, 2015).

\section{Referencias citadas}

Agamben, G. (2010): Estado de excepción, Valencia, Pre-textos.

Appadurai, A. (1981): “Gastro-politics in Hindu South Asia”, en American Ethnologist 8 (3), pp. 494-511, disponible en web: https://anthrosource.onlinelibrary. wiley.com/doi/pdf/10.1525/ae.1981.8.3.02a00050 [consultado el 03 de marzo 2021].

Araujo, K. (2016): El miedo a los subordinados, Una Teoría de la autoridad, Santiago, LOM Ediciones.

Araujo, K. (2017): “Sujeto y neoliberalismo en Chile: rechazos y apegos", en Nuevo Mundo Mundos Nuevos, disponible en web: https://doi.org/10.4000/nuevomundo.70649 [Consultado el: 06 agosto 2020].

Atria, F. (2013): Veinte años después. Neoliberalismo con rostro humano, Santiago, Catalonia.

Atria, F. (2017): La mala educación. Ideas que inspiran almovimiento estudiantil en Chile, Santiago, Catalonia.

Atria, F., Larraín, G., Benavente, J.M., Couso, J., Joignant, A. (2014): El otro modelo. Del orden neoliberal al régimen de lo público, Santiago, Debate.

Avelar, I. (2016): Figuras de la violencia. Ensayos sobre narrativa, política ymúsica popular, Santiago, Palinodia.

Badiou, A. (2020): “Sobre la situación epidémica”, en Sopa de Wuhan, Buenos Aires, Editorial ASPO, pp. 67-78.

Boron, A. (1999): “Capítulo IV. La trama del neoliberalismo: mercado, crisis y exclusión social”, en Emir Sade y Pablo Gentili (compiladores) La trama del neoliberalismo, Buenos Aires, EUDEBA, pp. 91-128.

Buttler, J. (2020): "El capitalismo tiene sus límites", en Sopa de Wuhan, Buenos Aires, Editorial ASPO, pp. 59-65.

Bourdieu, P. (2019): Curso de sociología general 1. Conceptos fundamentales, Buenos Aires, Siglo Veintiuno Editores.

Castro, E. (2018): Diccionario Foucault. Temas, conceptos y autores, Buenos Aires, Siglo Veintiuno Editores.

Castro-Gómez, S. (2015): Historia de la gubernamentalidad I. Razón de Estado, liberalismo y neoliberalismo en Michel Foucault, Bogotá, Siglo de Hombre Editores.

Clausewitz, C. (2005): De la guerra, Madrid, La esfera 
de los libros.

Esposito, R. (2011): Bíos. Biopolítica y filosofía, Buenos Aires, Amorrortu.

Fassin, D. (2018): Por una repolitización del mundo. Las vidas descartables como desafío del siglo XXI, Buenos Aires, Siglo Veintiuno Editores.

Foucault, M. (2000). Defender la sociedad. Buenos Aires: Fondo de Cultura Económica.

Foucault, M. (2013): Historia de la sexualidad 1. Lavoluntad de saber, Buenos Aires, Siglo Veintiuno Editores.

Foucault, M. (2016): Nacimiento de la biopolítica, Buenos Aires, Fondo de Cultura Económica.

Gallardo, B. (1985): El redescubrimiento del carácter social del problema del hambre: Las ollas comunes. Documento de trabajo $\mathrm{N}^{\circ} 247$, Santiago, FLACSO-Chile.

Garcés, M. (2012): El despertar de la sociedad. Los movimientos sociales de América Latina y Chile, Santiago, LOM Ediciones.

Geertz, C. (2003): La interpretación de las culturas, Barcelona, Gedisa.

Hardy, C. (1986): Hambre + Dignidad = Olla Común, Santiago, PET Academia de Humanismo Cristiano.

Lévi-Strauss, C. (1966): “The Culinary triangle”, en Partisan Review 33, (4) pp. 586-595.

Mayol, A. (2014): El derrumbe del modelo. Crisis de la economía de mercado en el Chile contemporáneo, San- tiago, LOM Ediciones.

Mayol, A y Ahumada, J. (2015): Economía política del fracaso. La falsa modernización del modelo neoliberal, Santiago, El desconcierto.

Mayol, P. (2006): “Capítulo I. El barrio”, en Michel de Certeau, Luce Giard y Pierre Mayol La invención de lo cotidiano 2. Habitar, cocinar, Ciudad de México, Universidad Iberoamericana, pp. 3-12.

Mbembe, A. (2011): Necropolítica, Tenerife, Editorial Melusina.

Montecino, S. (2021): El pelo de Chile y otros textos huachos. Ensayos y escritos breves, Santiago, Subdirección de Investigación del Servicio Nacional del Patrimonio Cultural.

Montecino, S. y Foerster, R. (2012): "Identidades en tensión: devenir de una etno y gastropolítica en Isla de Pascua", en Universum 27 (1), pp. 143-166, disponible en web: http://dx.doi.org/10.4067/S071823762012000100008 [consultado el 05 de marzo 2021].

Moraña, M. (2014): Inscripciones críticas. Ensayos sobre la cultura latinoamericana. Santiago, Editorial Cuarto propio.

Mouffe, C. (2011): En torno a lo político, Buenos Aires, Fondo de Cultura Económica.

Moulian, T. (1998): El consumo me consume, Santiago, LOM Ediciones.

Pincheira. I. (2018): “El Gobierno del miedo". En Luna Follegati y Rodrigo Karmy (comp.) Estudios en Guberna- 
mentalidad. Ensayos sobre poder, vida y neoliberalismo, Viña del Mar, Asociación Communes, pp. 231-280.

Ranciére, J. (2011): El malestar en la estética, Buenos Aires, Capital Cultural.

Reyes Jara, J. (2020): “Desigualdad y ollas comunes para combatir la pandemia", en CIPER. Disponible en Web: https:/ciperchile.cl/2020/06/19/desigualdad-y-ollas-comunes-para-combatir-la-pandemia/\#_ ftn1 [Consultado el: 26 de junio 2020].

Ruiz, C. (2020): Octubre chileno, la irrupción de un nuevo pueblo, Santiago, Editorial Taurus.

Salazar, G. (2012): Los movimientos sociales en Chile. Trayectoria histórica y proyección política, Santiago, Uqbar Editores.

Solnit, R. (2015): Wanderlust. Una historia del caminar, Santiago, Hueders.

\section{Notas}

[1] Sobre el fenómeno del miedo como técnica de gobierno en Chile véase Araujo (2016) y Pincheira (2018). Sobre el consumo véase Moulian (1998).

[2] Frases recogidas del portal de noticias El desconcierto.cl Disponible en: https://www.eldesconcierto. cl/2020/04/16/video-estamos-en-guerra-y-enemigo-poderoso-e-implacable-pinera-y-la-repeticion-de-conceptos-estos-ultimos-anos/ [consultado el 06 de junio 2020].

[3] Información recogida del portal de noticias de la radio Cooperativa Disponible en https://www. cooperativa.cl/noticias/pais/gobierno/presidencia-licito-compra-de-productos-gourmet-en-plena-pandemia/2020-06-23/154029.html [Consultado el 11 de junio de 2020]

[4] Frase recogida del sitio de noticias El mostrador Disponible en https://www.elmostrador.cl/dia/2020/05/28/ en-medio-de-la-pandemia-del-covid-19-manalichreconoce-que-en-santiago-hay-un-nivel-de-pobrezay-hacinamiento-del-cual-yo-no-tenia-conciencia/ [consultado el 13 de julio de 2020].

[5] Información recogida del portal Prensa Presidencia.cl. Disponible en: https://prensa.presidencia.cl/ comunicado.aspx?id=153015 [Consultado el 14 de julio de 2020].

[6] Según un estudio realizado por la Fundación Sol, $26 \%$ de los chilenos están morosos y contraen nuevas deudas para pagar las ya vencidas. Según Marco Kremerman, "un 82 \% de personas mayores de edad están endeudadas, más de 11 millones (en un país de 18 millones de habitantes)", El 75 \% de los hogares presenta algún tipo de endeudamiento, donde la mayoría de las deudas son por salud y educación. Si bien el endeudamiento afecta tanto a las clases altas como a las clases populares, “existe una 'segmentación' en cuanto al origen del crédito y a la institución con la que se contrata. En los grupos de mayores ingresos se contrae con la banca para financiar negocios, casas o coches, mientras que en los sectores más pobres la deuda es directamente con los comercios, retail, para la compra de comida o ropa". Disponible en http:// www.fundacionsol.cl/2019/08/un-26-de-los-chilenosson-morosos-y-contraen-nuevas-deudas-para-pagaranteriores/ [consultado el 17 de julio 2020]. 
[7] Dato proporcionado por Eve Crowley representante en Chile de la FAO, El mostrador. Disponible en: https:// www.elmostrador.cl/dia/2020/06/21/fao-en-chile-advierte-hasta-un-millon-de-personas-podrian-verse-privadas-de-alimentos-nutritivos-por-varios-dias/ [Consultado el 23 de julio de 2020].

[8] La expresión "aldeas potemkin" se utiliza para describir lo que a primera vista se ve muy bien presentado y que sirve para disimular el desastroso estado real de las cosas.

[9] Sobre las movilizaciones sociales en democracia véase Salazar (2012); Garcés (2012); Atria (2017).

[10] Las prácticas culturales desde una perspectiva antropológica implican el conjunto de "sistemas de valores subyacentes que estructuran las cuestiones fundamentales que están en juego en la vida cotidiana, inadvertidas a través de la consciencia de los sujetos, pero decisivas para su identidad individual y grupal" (Mayol, 2006: 7).

[11] Desde mi perspectiva me parece que existen dos elementos particulares de las ollas comunes hoy que divergen de los análisis que se hayan hecho en dictadura. El primero tiene directa relación con la pandemia la cual obliga a que su funcionamiento esté acotado a un grupo restringido de personas para minimizar contagios. La segunda tiene que ver con el uso de las redes sociales lo que ha permitido que el fenómeno de las ollas comunes sea mucho más visible, que gente de sectores más privilegiados e incluso desde el extranjero se involucren. Se requeriría llevar a cabo un estudio más acabado para poder determinar la especificidad del funcionamiento de las ollas comunes hoy en día y en pandemia.
[12] Sobre las distintas articulaciones populares que han tenido las ollas comunes en la historia de Chile, véase Bernarda Gallardo (1985, pp. 14-19).

[13] Solo a modo de ejemplo, a mediados del mes de junio, en la comuna de Lo Espejo "existen al menos 75 puntos en los que se producen alrededor de 8.000 raciones de comida a la semana. Esto equivale a 11 ollas comunes por kilómetro cuadrado" (Reyes Jara, 2020). 